\title{
In-silico ANALYSIS OF THE INHIBITORY ACTIVITIES OF NOVEL AZO DERIVATIVES OF BENZIMIDAZOLE ON Mycobacterium tuberculosis DPRE1
}

\author{
Geeta Mounika1, Anuradha Khuntia', Subhendu Nayak², B. Siva Kumar³, \\ N. Yellasubbaiah ${ }^{4}$, Tarun Kumar Sabbi ${ }^{1}$ and Sujit Kumar Mohanty, ${ }^{1}$ \} \\ ${ }^{1}$ Department of Pharmaceutical Chemistry, Shri Vishnu College of Pharmacy (Autonomous), \\ Bhimavaram, Andhra Pradesh-534202. \\ ${ }^{2}$ Scientist, IFF Inc., Madison, Wisconsin \\ ${ }^{3}$ Department of Pharmaceutical Chemistry, SRM College of Pharmacy, Kattankulathur-603203 \\ ${ }^{4}$ Department of Pharmaceutical Chemistry, Creative Educational Society's College of Pharmacy, \\ Kurnool \\ ${ }^{\circledR}$ Corresponding Author: sujit.m@svcp.edu.in
}

\begin{abstract}
DprE1 inhibitors were analysed by high-throughput screening against mycobacterial cells, which produce a new class of compounds known as anti-tubercular agents. DprE1 is a fundamental mycobacterial enzyme that is responsible for the synthesis of mycobacterial cell walls. DprE1 is identified as a new target and the compounds inhibiting this target are proved to be active against such mycobacterial cells that are resistant to conventionally available marketed TB drugs. In this interest, a set of some new azo benzimidazole, prepared by condensing diazonium derivatives of benzimidazole with different suitable aromatic derivatives, were used as ligand against Mycobacterium tuberculosis DprE1 receptor. For this purpose, the crystal structure of Mycobacterium tuberculosis DprE1 in complex with the non-covalent inhibitor QN118 (PDB ID: 4P8N, $1.79 \AA$ X-ray resolution) was retrieved from the RCSB Protein Database and used as the target. All the compounds were firmly inhibited by filling the active sites in the model with low energy values. The Present study backed that the anti-TB compounds designed by Mohanty et al. (2018) justify their in silico inhibitory property on DprE1. So, these compounds can be of clinical importance against specific diseases that may be related to the protein DprE1.
\end{abstract}

Keywords: In silico, Azo Derivatives, Benzimidazole, DprE1, Anti-tubercular

RASĀYAN J. Chem., Vol. 14, No.3, 2021

\section{INTRODUCTION}

Tuberculosis is a life-threatening infectious disease and as per W.H.O, multidrug-resistant tuberculosis (MDR-TB) has been developed in 490,000 people in the world in 2014 and more than 1.5 billion US dollars is needed per year to fill resource gaps for executing existing TB treatment protocol. Lots of steps have been taken by various responsible organizations to treat tuberculosis, but the fight is still not won. Benzimidazole is a privileged heterocyclic organic compound that is similar to nucleotides present in the human body and so is a potent pharmacophore in developing new medicinal entities. The benzimidazole moiety is attracting increasing importance in drug design, and many drugs having benzimidazole structure exhibit potent pharmacological properties such as antitubercular, anticancer, or antiviral. ${ }^{1}$

The present analysis was designed to examine the antagonistic properties of previously synthesized compounds on Mycobacterium DprE1, their interaction parameters and drug-like properties. In this current study, Mycobacterium DprE1 3D structure is used as a receptor against designed azo derivatives of benzimidazoles. (Fig.-1). DprE1, an oxidoreductase enzyme present in mycobacteria, has a Flavin binding domain and substrate-binding domain through which it involves in cell wall synthesis of mycobacterium. ${ }^{2,3}$ This DprE1 was inhibited by benzothiazinone nucleus and most importantly by the BTZ043, one of the NCE's used to understand the binding properties of DprE1.benzothiazinone binds to the amino acids like His132, Gly133, Lys134, Lys367, Phe369, Asn385 in the hydrophobic pocket and to Rasayan J. Chem., 14(3), 1565-1572(2021) 
RASĀYAN J. Chem.

Vol. 14 | No. 3 |1565-1572| July - September | 2021

Gly117 and Val365. So, these amino acids make up the active site in DprE1. ${ }^{4-6}$ Binding site of Mycobacterium DprE1 was selected and in silico analysis was performed via docking. All docked ligands were studied carefully for finding the exact interaction of these compounds on the receptor's active site. ${ }^{7}$

\section{EXPERIMENTAL}

\section{Ligand Dataset}

According to Mohanty et al., a set of new azo benzimidazoles, which were synthesized by coupling diazonium benzimidazoles with different aromatic compounds, were used in docking studies against the receptor (PDB ID:4P8N). Figure-1 represents structures and IUPAC names of this series named as compounds 6(a1-a5) and 6(b1-b5).

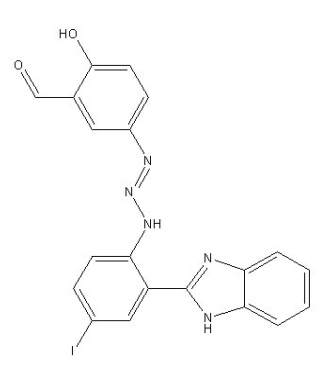

$6 \mathrm{a} 1$

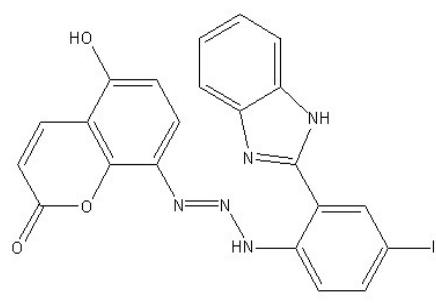

$6 \mathrm{a} 5$

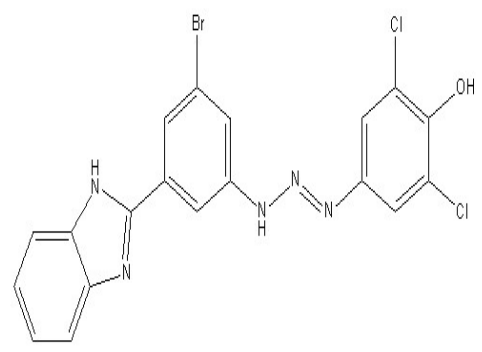

$6 \mathrm{~b} 3$

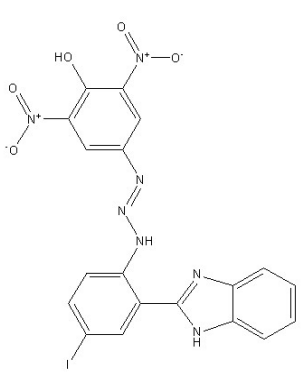

$6 \mathrm{a} 2$

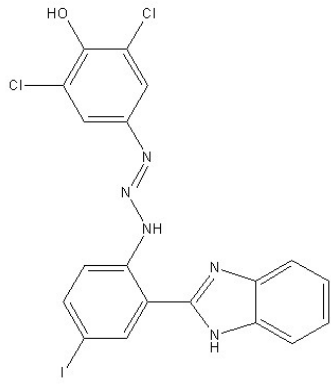

$6 \mathrm{a} 3$

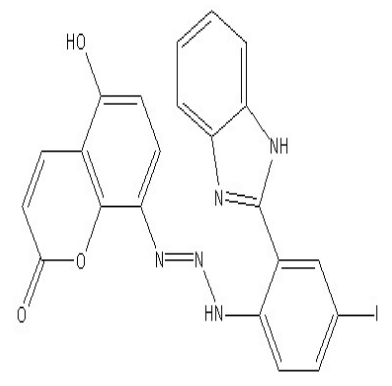

$6 \mathrm{a} 4$<smiles>O=Cc1cc(N=NNc2cc(Br)cc(-c3nc4ccccc4[nH]3)c2)ccc1O</smiles>

$6 \mathrm{~b} 1$

$6 \mathrm{~b} 2$

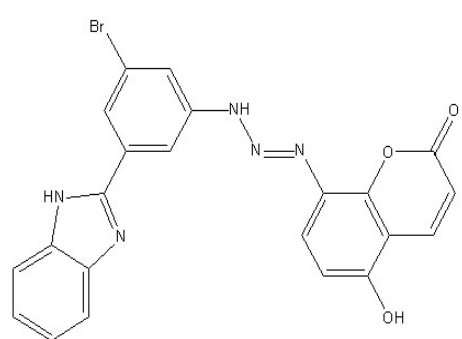

$6 b 4$

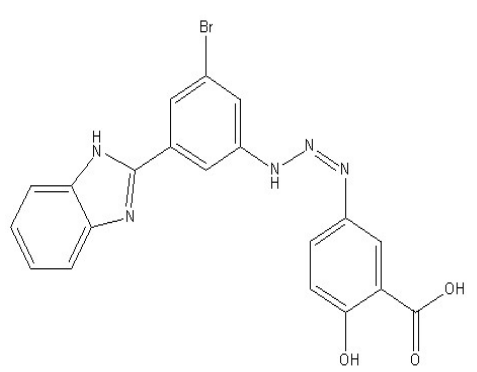

$6 \mathrm{~b} 5$

Fig.-1: 2D Structure of Azo derivatives of benzimidazole (6a1-6a5 and 6b1-6b5).

$6 \mathrm{a} 1$ (E)-5-(3-(2-(1H-benzo[d]imidazol-2-yl)-4-iodophenyl)triaz-1-en-1-yl)-2-hydroxybenzaldehye; $6 \mathrm{a} 2$ (E)-4-(3-(2-(1H-benzo[d]imidazol-2-yl)-4-iodopheny)triaz-1-en-1-yl)-2,6-dinitrophenol; 6 a3 (E)-4-(3-(2-(1H-benzo[d]imidazol-2-yl)-4-iodophenyl)triaz-1-en-1-yl)-2,6-dichlorophenol; $6 \mathrm{a} 4$ (E)-8-(3-(2-(1H-benzo[d]imidazol-2-yl)-4-iodophenyl)triaz-1-en-1-yl)-5-hydroxy-2H-chromen-2-one; 6 5 (E)-4-(3-(2-(1H-benzo[d]imidazol-2-yl)-4-iodophenyl)triaz-1-en-1-yl)-2-hydroxybenzoic acid;

$6 \mathrm{~b} 1$ (E)-5-(3-(3-(1H-benzo[d]imidazol-2-yl)-5-bromophenyl)triaz-1-en-1-yl)-2-hydroxybenzaldehyde; $6 \mathrm{~b} 2$ (E)-4-(3-(3-(1H-benzo[d]imidazol-2-yl)-5-bromophenyl)triaz-1-en-1-yl)-2,6-dinitrophenol; 6 b3 (E)-4-(3-(3-(1H-benzo[d]imidazol-2-yl)-5-bromophenyl)triaz-1-en-1-yl)-2,6-dichlorophenol; $6 b 4$ 8-(3-(3-(1H-benzo[d]imidazol-2-yl)-5-bromophenyl)triaz-1-en-1-yl)-5-hydroxy-2H-chromen-2-one; 6 b5 (Z)-5-(3-(3-(1H-benzo[d]imidazol-2-yl)-5-bromophenyl)triaz-1-en-1-yl)-2-hydroxybenzoic acid. 
RASĀYAN J. Chem.

Vol. 14 | No. 3 |1565-1572| July - September | 2021

\section{Structure Prediction}

The crystal structure of DprE1 in complex with the non-covalent inhibitor QN118 (PDB ID: 4P8N, 1.79 $\AA$ X-ray resolution) was obtained from the RCSB Protein Database (PDB). Three-dimensional structure of receptor protein ${ }^{8}$ mycobacterium DprE1 (PDB ID: 4P8N) is known experimentally and is shown in Fig.-2.

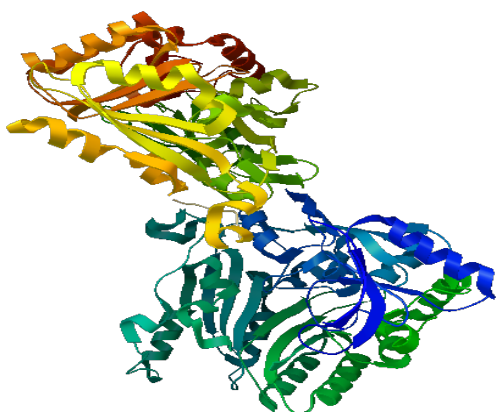

Fig.-2: 3D Secondary Structure of Receptor Protein 4P8N with a resolution of $1.79 \mathrm{~A}^{\circ}$

The structural analysis of the protein was performed and is validated using MGL tools, ${ }^{9}$ Ramachandran plots, ${ }^{10}$ PROCHECK and ERRAT tools ${ }^{11,12}$ and is presented in Fig.-3.

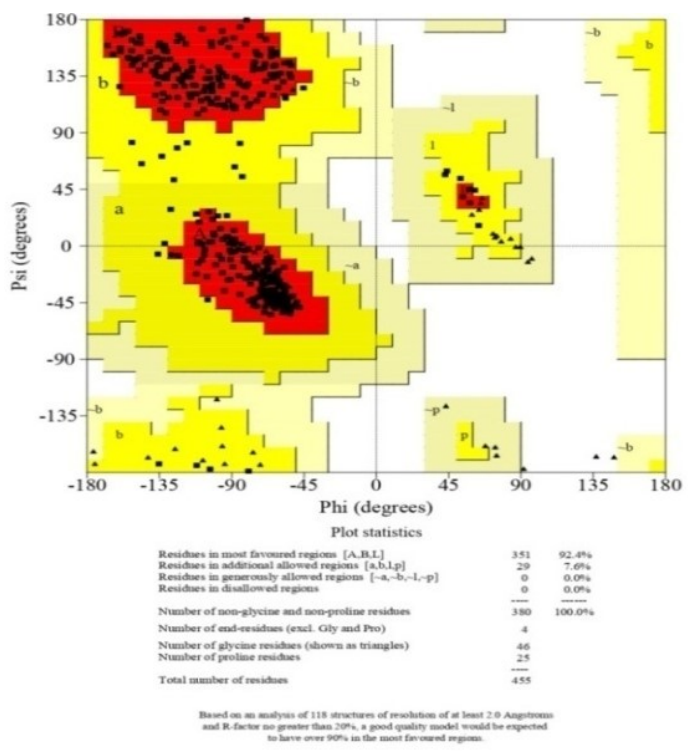

(a)
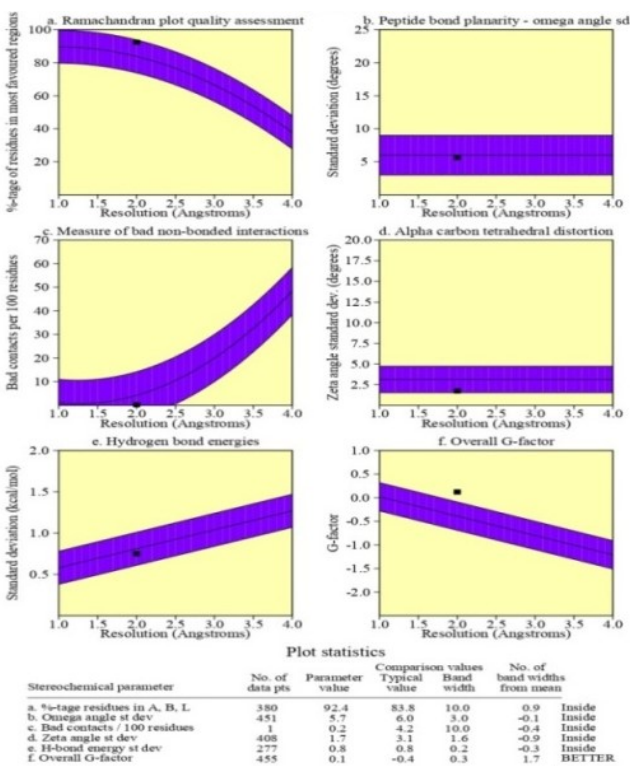

(b)

Fig.-3: Structure Validation of modelled protein, 4P8N(a) Ramachandran Plot representing 99.6\% residues in the favourable region. (b) PROCHECK validation plot for Active Chain Parameters.

\section{Molecular Docking}

Automated dockings were performed by using various tools of AutoDock 4.2, for determining the orientation of designed ligands (azo benzimidazoles) binding to the selected site of $4 \mathrm{P} 8 \mathrm{~N} .{ }^{13}$ Polar hydrogens and Kollmann charges were added to the receptor. All the non-polar hydrogens present in the ligand structure were fused followed by allotment of Gasteiger partial charges. Rotations were enabled for the bonds present in all the ligands, in this procedure, random orientations and torsions were also used. Grid maps were optimized by using Autogrid carefully. Docked conformation having the lowest binding energy was identified for every selected ligand. ${ }^{14}$

\section{Active Binding Residues}

With the help of PDB (ID: 4P8N), all the active site residues present in the receptor were identified and docking studies were carried out.

Residues extracted: Gly 117, His 132, Lys 134, Ser 228, Trp 230, Val 365, Tyr 415 and Lys 418. 
RASĀYAN J. Chem.

Vol. 14 | No. 3 |1565-1572| July - September | 2021

\section{Structure Validation}

\section{RESULTS AND DISCUSSION}

Crystal structure of 4P8N (resolution $1.5 \mathrm{~A}^{\circ}$ ) was used. Ramachandran plot represented $99.6 \%$ residues in the favourable area and none were present in the unfavourable portion. In addition to this, the other important parameters such as peptide bond planarity, tetrahedral distortion, non-bonded interactions, main chain $\mathrm{H}$ bond energy and total $\mathrm{G}$ factor for the selected structure are present inside the allowed range. The total quality factor for non-bonded interactions was well high above the allowed range i.e., 98.6604 which reflected the quality of the selected model. Figure-3 represents the structure verification by Ramachandran plot, ERRAT programs and PROCHECK. All the above data verified that the selected model is of high quality and can be used for performing further studies.

\section{Molecular Dockings}

Docking studies were performed with the receptor protein. All the selected ligands produced low binding energy values as represented in Table-1. The potency of all the ligands to inhibit the target was proved by their energy values. The binding energy values were found to be in the range between -9.6 to -10.7 $\mathrm{kcal} / \mathrm{mol}$. The $\mathrm{H}$ bond energy values were found to be in the range between -2.443 to $-6.798 \mathrm{kcal} / \mathrm{mol}$. Moreover, the intermolecular energy values, Hydrogen bond and electrostatic energy values were also found to be in acceptable limit for the selected protein and are represented in Table-1.

Table-1: Different Energy Values of Docked Compounds with Receptor Protein, 4P8N

\begin{tabular}{|c|c|c|c|c|c|c|}
\hline \multirow{2}{*}{ S. No. } & \multirow{2}{*}{ Compounds } & \multirow{2}{*}{$\begin{array}{c}\text { Binding } \\
\text { Energy } \\
(\mathrm{kcal} / \mathrm{mol})\end{array}$} & \multicolumn{2}{|c|}{$\begin{array}{c}\text { Hydrogen Bond } \\
\text { Energy }(\mathrm{kcal} / \mathrm{mol})\end{array}$} & \multirow{2}{*}{$\begin{array}{c}\text { Hydrogen } \\
\text { Bond Energy } \\
(\mathrm{kcal} / \mathrm{mol})\end{array}$} & \multirow{2}{*}{$\begin{array}{c}\text { Torsional Free } \\
\text { Energy } \\
(\mathrm{kcal} / \mathrm{mol})\end{array}$} \\
\hline & & & $\begin{array}{l}\text { Ideal } \\
\text { Value }\end{array}$ & $\begin{array}{c}\text { Std. } \\
\text { Deviation }\end{array}$ & & \\
\hline 1 & $6 \mathrm{a} 1$ & -9.6 & -2.0 & 0.8 & - & 1.00 \\
\hline 2 & $6 \mathrm{a} 2$ & -10.2 & -2.0 & 0.8 & -4.378 & 1.00 \\
\hline 3 & $6 a 3$ & -9.8 & -2.0 & 0.8 & - & 1.00 \\
\hline 4 & $6 \mathrm{a} 4$ & -10.4 & -2.0 & 0.8 & -6.798 & 1.00 \\
\hline 5 & $6 a 5$ & -10.4 & -2.0 & 0.8 & - & 1.00 \\
\hline 6 & $6 \mathrm{~b} 1$ & -10.2 & -2.0 & 0.8 & - & 1.00 \\
\hline 7 & $6 \mathrm{~b} 2$ & -10 & -2.0 & 0.8 & -2.491 & 1.00 \\
\hline 8 & $6 \mathrm{~b} 3$ & -9.6 & -2.0 & 0.8 & -2.443 & 1.00 \\
\hline 9 & $6 \mathrm{~b} 4$ & -10.7 & -2.0 & 0.8 & - & 1.00 \\
\hline 10 & $6 \mathrm{~b} 5$ & -10.5 & -2.0 & 0.8 & -2.976 & 1.00 \\
\hline
\end{tabular}

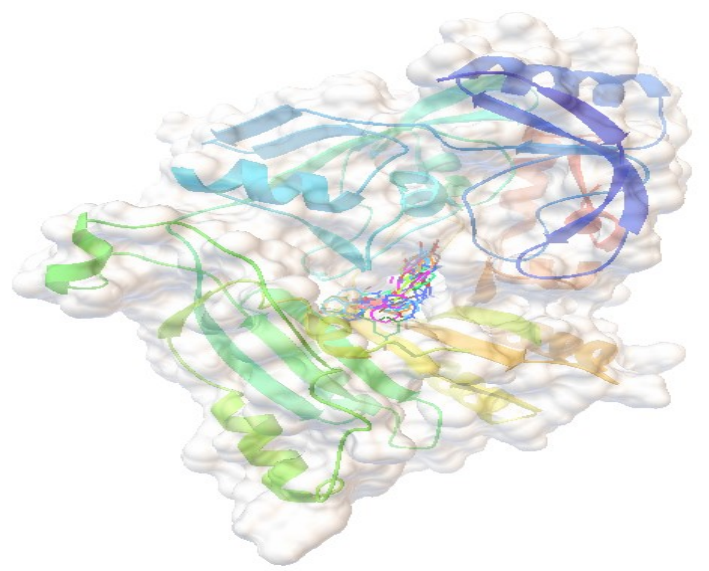

Fig.-4: Binding Orientation of all Azo Derivatives of Benzimidazole in Receptor Protein, 4P8N.

\section{Binding Mode of Azo Derivatives of Benzimidazole}

All azo derivatives of benzimidazoles are bound efficiently with binding sites of receptor protein, $4 \mathrm{P} 8 \mathrm{~N}$. Figure- 4 shows the binding mode of the compounds with $4 \mathrm{P} 8 \mathrm{~N}$. It clearly shows that all compounds bind 
RASĀYAN J. Chem.

Vol. 14 | No. 3 |1565-1572| July - September | 2021

in the same pocket in the protein. Figure-5 represents the binding residues with the receptor. Interaction of receptor protein, $4 \mathrm{P} 8 \mathrm{~N}$ with the compounds $6 \mathrm{a} 1-6 \mathrm{a} 5$ and $6 \mathrm{~b} 1-6 \mathrm{~b} 5$ was studied further in detail. Table- 2 outlines the results of the binding residue for compounds 6a1-6a5 and 6b1-6b5. It was observed that all residues of the receptor active site were involved in binding with the ligands. Potent binding inhibitions are also proved by the number of hydrogen bonds as presented in Table-3 and Fig.- 6 . Compound $6 \mathrm{~b} 5$ makes 2 hydrogen bonds with 2 residues. Arg325 and Gln334 of 4P8N protein were engaged in forming hydrogen bonds with these ligands; however, His 132 was the highest occurring residue forming hydrogen bonding. Compounds $6 \mathrm{a} 2,6 \mathrm{a} 4,6 \mathrm{~b} 2$, and $6 \mathrm{~b} 3$ form one hydrogen bond with Gly117, Trp230, Tyr60 and Lys418, as shown in Table-3. Compounds $6 \mathrm{a} 1,6 \mathrm{a} 3,6 \mathrm{a} 5,6 \mathrm{~b} 1$ and $6 \mathrm{~b} 4$ do not form any hydrogen bond with any of the residues of the receptor protein, $4 \mathrm{P} 8 \mathrm{~N}$.

Figure- 6 shows the interacting residues involved in docking of the compounds with the active site of receptor protein, $4 \mathrm{P} 8 \mathrm{~N}$. Compound $6 \mathrm{a} 1$ forms no hydrogen bonds and only interacts hydrophobically with Gly117, His132, Ser228, Val365 and Lys418 (Fig.-6a). Compound 6a2 forms one hydrogen bond with Gly117 $\left(2.051 \mathrm{~A}^{\circ}\right)$, while it interacted hydrophobically with Gly117, His132, Lys134, Ser228, Trp230, Val365, Tyr415 and Lys418 as shown in the Fig.-6b. Compound 6a3 also forms no hydrogen bonds and interacts hydrophobically with Gly117, His132, Ser228, Trp230, Val365, Lys 418 (Fig.-6c). Compound 6a4 forms one hydrogen bond with $\operatorname{Trp} 230\left(1.903 \mathrm{~A}^{\circ}\right)$ and interacted hydrophobically with Gly 117 , His132, Ser228, Trp230, Val365, and Lys418 (Fig.-6d). Compound 6a5 forms no hydrogen bonds and interacted hydrophobically with Gly117, His132, Lys134, Ser228, Val365, and Lys418 (Fig.-6e). Compound $6 \mathrm{~b} 1$ forms no hydrogen bonds and interacted hydrophobically with His132, Lys134, Ser228, Trp230, Tyr415 and Lys418 (Fig.-6f). Compound 6b2 forms one hydrogen bond with Tyr60 (2.116 A $)$ and interacted hydrophobically with His132, Lys134, Val365, and Tyr415 (Fig.-6g). Compound 6b3 forms one hydrogen bond with Lys418 $\left(2.059 \mathrm{~A}^{\circ}\right)$, while it interacted hydrophobically with Gly117, His132, Ser228, Tyr415 and Lys418 (Fig.-6h). Compound 6b4 forms no hydrogen bonds and it interacted hydrophobically with Lys134, Ser228, Trp230, and Val365. (Fig.-6i). Compound 6b5 forms two hydrogen bonds with $\operatorname{Arg} 325\left(1.897 \mathrm{~A}^{\circ}\right)$ and $\operatorname{Gln} 334\left(2.117 \mathrm{~A}^{\circ}\right)$ while it interacted hydrophobically with Gly117, His132, Lys134, Tyr415 and Lys418 (Fig.-6j).

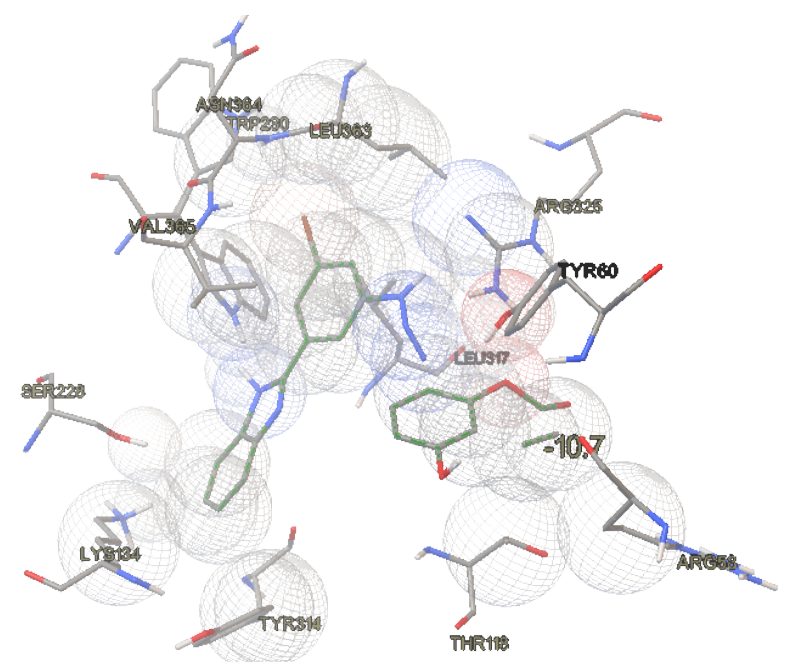

Fig.-5: Various Residues engaged in binding with the Target Protein. All the Compounds are represented in sticks encircled by the mesh surface. Target Residues are represented in Sticks

Table-2: Receptor Protein, 4P8N, Active Site residues engaged in Docking Interactions with the Ligands

\begin{tabular}{c|c|c|c|c|c|c|c|c}
\hline \multirow{2}{*}{ Compounds } & \multicolumn{7}{c}{ Binding Residues } \\
\cline { 2 - 9 } & Gly117 & His132 & Lys134 & Ser228 & Trp230 & Val365 & Tyr415 & Lys418 \\
\hline 6a1 & $\checkmark$ & $\checkmark$ & & $\checkmark$ & & $\checkmark$ & $\checkmark$ & \\
\hline $6 \mathrm{a} 2$ & $\checkmark$ & $\checkmark$ & $\checkmark$ & $\checkmark$ & $\checkmark$ & & $\checkmark$ & $\checkmark$ \\
\hline $6 \mathrm{a} 3$ & & $\checkmark$ & $\checkmark$ & $\checkmark$ & & & & $\checkmark$ \\
\hline
\end{tabular}


RASĀYAN $J$. Chem.

Vol. 14 | No. 3 |1565-1572| July - September | 2021

\begin{tabular}{c|c|c|c|c|c|c|c|c}
\hline $6 \mathrm{a} 4$ & $\checkmark$ & $\checkmark$ & & $\checkmark$ & & $\checkmark$ & $\checkmark$ & \\
\hline $6 \mathrm{a} 5$ & $\checkmark$ & $\checkmark$ & $\checkmark$ & & $\checkmark$ & & & \\
\hline $6 \mathrm{~b} 1$ & $\checkmark$ & & & & & & $\checkmark$ & $\checkmark$ \\
\hline $6 \mathrm{~b} 2$ & $\checkmark$ & $\checkmark$ & $\checkmark$ & $\checkmark$ & $\checkmark$ & $\checkmark$ & & $\checkmark$ \\
\hline $6 \mathrm{~b} 3$ & & $\checkmark$ & & $\checkmark$ & $\checkmark$ & $\checkmark$ & & \\
\hline $6 \mathrm{~b} 4$ & & $\checkmark$ & & $\checkmark$ & $\checkmark$ & & $\checkmark$ & $\checkmark$ \\
\hline $6 \mathrm{~b} 5$ & & $\checkmark$ & $\checkmark$ & & & $\checkmark$ & & \\
\hline
\end{tabular}

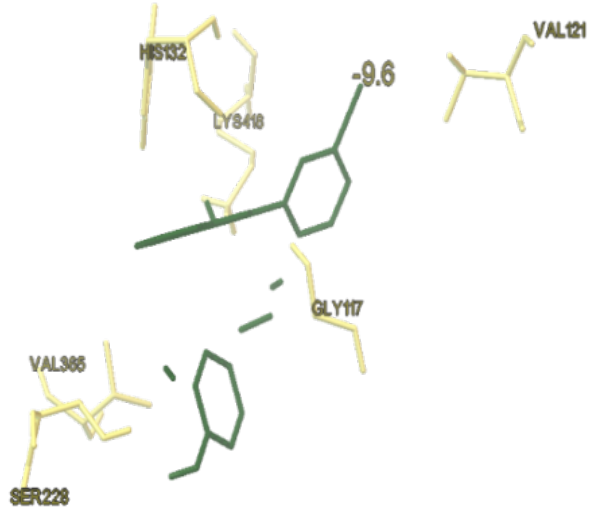

a

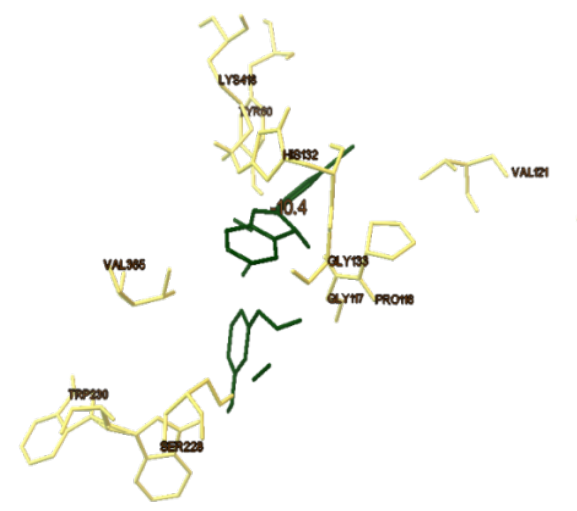

d

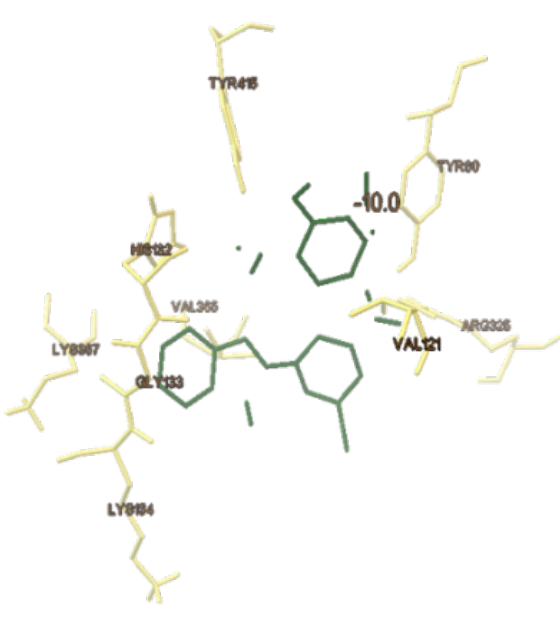

g

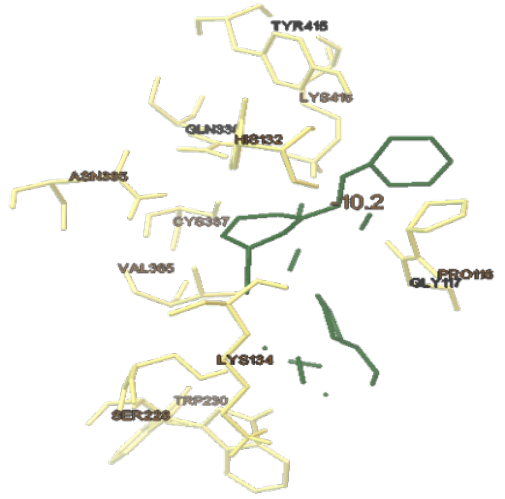

b

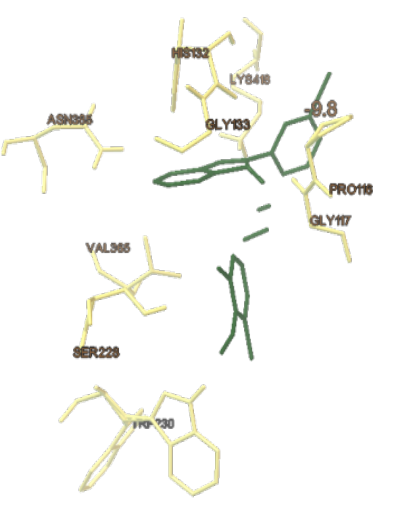

$\mathrm{c}$

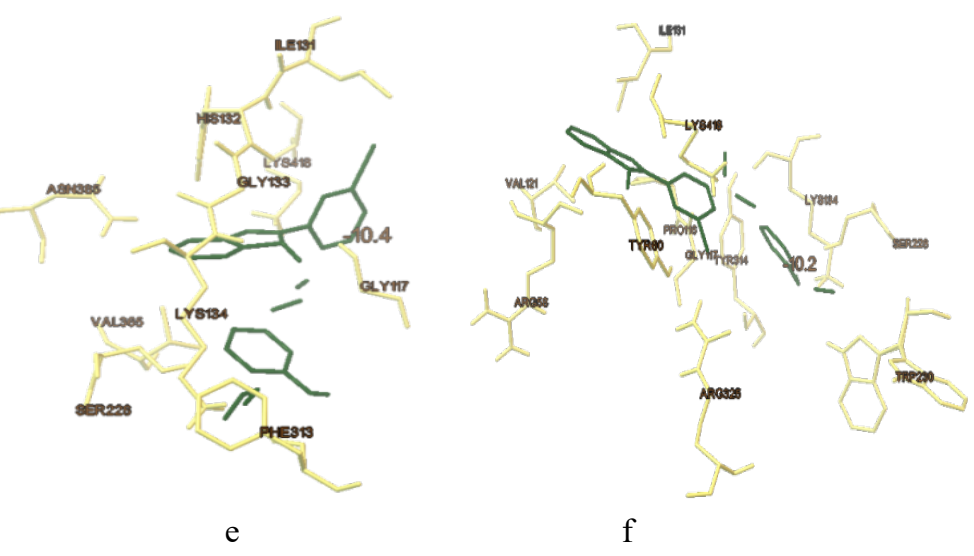

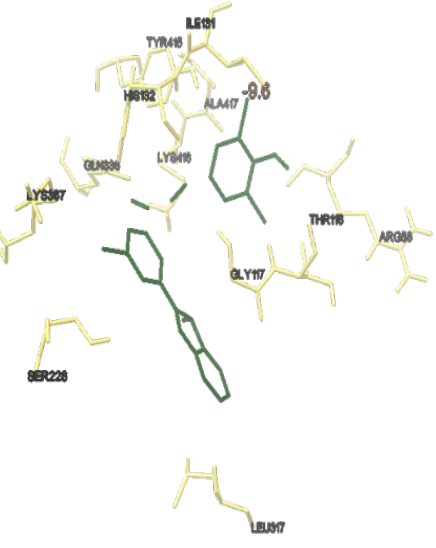

h

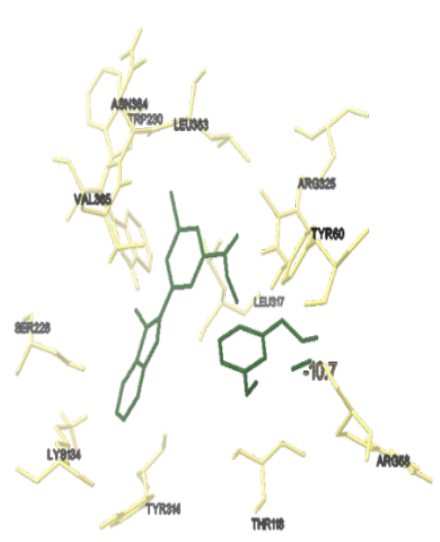

$\mathrm{i}$ 
RASĀYAN J. Chem.

Vol. 14 | No. 3 |1565-1572| July - September | 2021

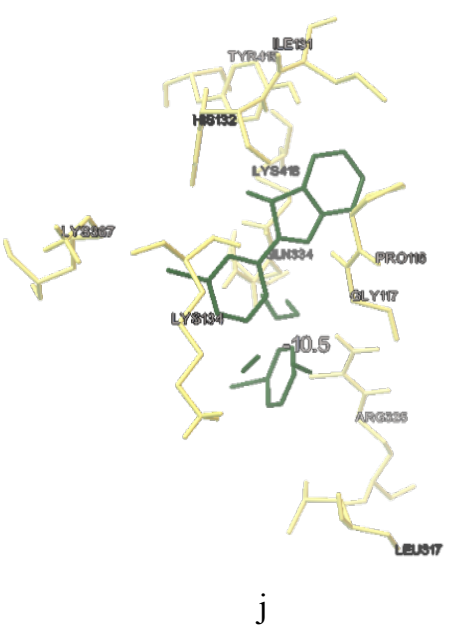

Fig.-6: Binding Site Residues of Protein 4P8N with ligands. Compounds 6a1-6a5 and 6b1-6b5 shows the binding mode with the receptor protein. a: 6a1, b: 6a2, c: 6a3, d:6a4, e: 6a5, f: 6b1, g: 6b2, h: 6b3, i: 6b4, j: 6b5

Table-3: Compounds, Target Protein Residues involved in forming Hydrogen Bonds and Bond Distance

\begin{tabular}{c|c|c|c|c|c}
\hline S. No. & Compounds & No. of H Bonds & Binding Residue & H bond & Distance $\left(\mathrm{A}^{\circ}\right)$ \\
\hline 1 & $6 \mathrm{a} 1$ & 0 & - & - & - \\
\hline 2 & $6 \mathrm{a} 2$ & 1 & Gly117 & HN-H & 2.051 \\
\hline 3 & $6 \mathrm{a} 3$ & 0 & - & - & - \\
\hline 4 & $6 \mathrm{a} 4$ & 1 & Trp230 & O-H & 1.903 \\
\hline 5 & $6 \mathrm{a} 5$ & 0 & - & - & - \\
\hline 6 & $6 \mathrm{~b} 1$ & 0 & - & - & - \\
\hline 7 & $6 \mathrm{~b} 2$ & 1 & Tyr60 & N-H & 2.116 \\
\hline 8 & $6 \mathrm{~b} 3$ & 1 & Lys418 & N-H & 2.059 \\
\hline 9 & $6 \mathrm{~b} 4$ & 0 & - & - & - \\
\hline \multirow{2}{*}{10} & \multirow{2}{*}{$6 \mathrm{~b} 5$} & 2 & Arg325 & O-H & 1.897 \\
\cline { 3 - 6 } & & \multirow{2}{*}{2} & Gln334 & H-O & 2.117 \\
\hline
\end{tabular}

\section{Abbreviations}

DprE1: Decaprenylphosphoryl- $\beta$-d-ribose 2'-epimerase

IUPAC: International union of pure and applied chemistry.

RCSB: Research Collaboratory for Structural Bioinformatics

MGL: Molecular Graphics Laboratory; His: Histidine; Val: Valine; Lys: Lysine; Thr: Threonine; Arg: Arginine; Asn: Asparagine; Leu: Leucine; Phe: Phenyl alanine

\section{CONCLUSION}

This In silico analysis of the inhibitory activities of novel azo derivatives of benzimidazole on Mycobacterium tuberculosis DprE1 supports the in-vitro antitubercular activity published by Mohanty et. al. and can be further developed as potent agents for the treatment of TB. It was analyzed that the ligands have strong Inhibitory binding potencies with active site residues in the range of -9.6 to $-10.7 \mathrm{kcal} / \mathrm{mol}$. The Hydrogen bond energy values were found to be in the range from -2.443 to $-6.798 \mathrm{kcal} / \mathrm{mol}$. Moreover, the intermolecular energy values $+\mathrm{H}$ bond + electrostatic energy values were also found in a favourable range for the selected receptor protein. Low binding energy values revealed that these compounds are active scaffolds and can be considered in the design of new drugs against diseases related to the protein mycobacterial DprE1.

\section{ACKNOWLEDGEMENT}

The authors would like to acknowledge Shri Vishnu College of Pharmacy, Bhimavaram for providing the molecular modelling lab and other facilities. 
RASĀYAN J. Chem.

Vol. 14 | No. 3 |1565-1572| July - September | 2021

\section{REFERENCES}

1. S. K. Mohanty, A. Khuntia, N. Yellasubbaiah, C. Ayyanna, B. Naga Sudha and M. S. Harika, BeniSuef University Journal of Basic and Applied Sciences, 7(4), 646(2018), https://doi.org/10.1016/j.bjbas.2018.07.009

2. G. Riccardi, M. R. Pasca, L. R. Chiarelli, G. Manina, A. Mattevi and C. Binda, Applied Microbiology and Biotechnology, 97(20), 8841(2013), https://doi.org/10.1007/s00253-013-5218-x

3. R. V. Chikhale, M. A. Barmade, P. R. Murumkar and M. R. Yadav, Journal of Medicinal Chemistry, 61(19), 8563(2018), https://doi.org/10.1021/acs.jmedchem.8b00281

4. J. Piton, C. S. Y. Foo and S. T. Cole, Drug Discovery Today, 22(3), 526(2017), https://doi.org/10.1016/j.drudis.2016.09.014

5. I. Bhutani, S. Loharch, P. Gupta, R. Madathil and R. Parkesh, PLoS ONE, 10(3), e0119771(2015), https://doi.org/10.1371/journal.pone.0119771

6. X. Lu, G. Chao, S. Yao-Jie, T. Xin, R. Juan, L. Kun-Lin, P. Cui-Ting, W. Ning-Yu, L. Qian, Z. YiWen, Y. Luo-Ting and W. Yu-Quan, RSC Advances, 20(8), 11163(2018), https://doi.org/10.1039/C8RA00720A

7. S. Rai, U. Raj, S. Tichkule, H. Kumar, S. Mishra, N. Sharma, R. Buddham, D. Raghav and P. K. Varadwaj, International Journal for Computational Biology, 5(1), 54(2016), https://doi.org/10.34040/IJCB.5.1.2015.71

8. J. U. Bowie, R. Luthy and D. Eisenberg, Science, 253(5016), 164(1991), https://doi.org/10.1126/science.1853201

9. L. Ravi and K. Kannabiran, Innovare Journal of Medical Sciences, 4(3), 28(2016).

10. G. J. Kleywegt and T. A. Jones, Structure, 4(12), 1395(1996), https://doi.org/10.1016/s09692126(96)00147-5

11. R. A. Laskowski, M. W. MacArthur, D. S. Moss and J. M. Thornton, Journal of Applied Crystallography, 26(2), 283(1993), https://doi.org/10.1107/S0021889892009944

12. K. Arnold, L. Bordoli, J. Kopp and T. Schwede, Bioinformatics, 22(2), 195(2006), https://doi.org/10.1093/bioinformatics/bti770

13. T. J. Ewing, S. Makino, G. Skillman and I. D. Kuntz, Journal of Computer-Aided Molecular Design, 15, 411(2001), https://doi.org/10.1023/A:1011115820450

14. H. Iftikhar, S. Batool, A. Deep, B. Narasimhan, P. C. Sharma and M. Malhotra, Arabian Journal of Chemistry, 10(1), S1267(2017), https://doi.org/10.1016/j.arabjc.2013.03.007

[RJC-6398/2020] 